\title{
Article \\ Krill Oil Inhibits NLRP3 Inflammasome Activation in the Prevention of the Pathological Injuries of Diabetic Cardiomyopathy
}

\author{
Xuechun Sun ${ }^{1,2}$, Xiaodan Sun ${ }^{3}$, Huali Meng ${ }^{1,2}$, Junduo $\mathrm{Wu}^{4}$, Xin Guo ${ }^{1,2}$, Lei Du ${ }^{1,2, *(\mathbb{C})}$ and Hao Wu ${ }^{1,2, *}$ \\ 1 Department of Nutrition and Food Hygiene, School of Public Health, Cheeloo College of Medicine, \\ Shandong University, 44 Wenhuaxi Rd., Jinan 250012, China; 201915788@mail.sdu.edu.cn (X.S.); \\ 201915787@mail.sdu.edu.cn (H.M.); xguo@sdu.edu.cn (X.G.) \\ 2 Research Center of Translational Medicine, Jinan Central Hospital, Cheeloo College of Medicine, \\ Shandong University, 105 Jiefang Rd., Jinan 250013, China \\ 3 Intensive Care Unit, The Second Hospital, Cheeloo College of Medicine, Shandong University, \\ 247 Beiyuan Rd., Jinan 250033, China; xdsun@email.sdu.edu.cn \\ 4 Department of Cardiology, The Second Hospital of Jilin University, 218 Ziqiang St., Changchun 130041, China; \\ wujd@jlu.edu.cn \\ * Correspondence: dulei@sdu.edu.cn (L.D.); hwu@sdu.edu.cn (H.W.)
}

Citation: Sun, X.; Sun, X.; Meng, H.; Wu, J.; Guo, X.; Du, L.; Wu, H. Krill Oil Inhibits NLRP3 Inflammasome Activation in the Prevention of the Pathological Injuries of Diabetic Cardiomyopathy. Nutrients 2022, 14, 368. https://doi.org/10.3390/ nu14020368

Academic Editor: Lu Cai

Received: 7 December 2021

Accepted: 9 January 2022

Published: 15 January 2022

Publisher's Note: MDPI stays neutral with regard to jurisdictional claims in published maps and institutional affiliations.

Copyright: (C) 2022 by the authors. Licensee MDPI, Basel, Switzerland. This article is an open access article distributed under the terms and conditions of the Creative Commons Attribution (CC BY) license (https:// creativecommons.org/licenses/by/ $4.0 /)$.

\begin{abstract}
Diabetic cardiomyopathy (DCM) is a common complication of diabetes mellitus (DM), resulting in high mortality. Myocardial fibrosis, cardiomyocyte apoptosis and inflammatory cell infiltration are hallmarks of DCM, leading to cardiac dysfunction. To date, few effective approaches have been developed for the intervention of DCM. In the present study, we investigate the effect of krill oil (KO) on the prevention of DCM using a mouse model of DM induced by streptozotocin and a highfat diet. The diabetic mice developed pathological features, including cardiac fibrosis, apoptosis and inflammatory cell infiltration, the effects of which were remarkably prevented by KO. Mechanistically, $\mathrm{KO}$ reversed the DM-induced cardiac expression of profibrotic and proinflammatory genes and attenuated DM-enhanced cardiac oxidative stress. Notably, KO exhibited a potent inhibitory effect on NLR family pyrin domain containing 3 (NLRP3) inflammasome that plays an important role in DCM. Further investigation showed that KO significantly upregulated the expression of Sirtuin 3 (SIRT3) and peroxisome proliferator-activated receptor- $\gamma$ coactivator $1 \alpha$ (PGC- $1 \alpha)$, which are negative regulators of NLRP3. The present study reports for the first time the preventive effect of $\mathrm{KO}$ on the pathological injuries of DCM, providing SIRT3, PGC- $1 \alpha$ and NLRP3 as molecular targets of KO. This work suggests that $\mathrm{KO}$ supplementation may be a viable approach in clinical prevention of DCM.
\end{abstract}

Keywords: krill oil; NLRP3 inflammasome; diabetes; diabetic cardiomyopathy

\section{Introduction}

The prevalence of diabetes mellitus (DM) is increasing dramatically worldwide. The global DM prevalence is estimated to be $10.2 \%$ (578 million) by 2030 and $10.9 \%$ (700 million) by 2045 [1]. Diabetic cardiomyopathy (DCM) is a common complication of DM, exhibiting pathophysiological abnormalities, including inflammation, oxidative/nitrosative stress, cardiomyocyte apoptosis and accumulation of fibrosis in the heart [2]. Eventually, DCM results in heart failure [3]. The current strategies to prevent DCM are far from satisfactory. Hence, it is important to develop more effective approaches for the prevention of DCM.

Inflammation and oxidative stress are key mechanisms in the pathogenesis of DCM [4]. DM induces the expression of a series of cardiac proinflammatory genes, leading to the infiltration of inflammatory cells in the heart [4]. In addition, DM stimulates the formation of cellular reactive oxygen species and advanced glycation end products that enhance oxidative stress [4]. The DM-induced cardiac inflammation and oxidative stress boost mutually, forming a vicious circle that results in detrimental effects, such as apoptosis 
of cardiomyocytes and formation of fibrosis [5]. Therefore, targeting inflammation and oxidative stress is a viable strategy for the intervention of DCM.

Omega-3 fatty acids, especially docosahexaenoic acid (DHA) and eicosapentaenoic acid (EPA), are known to have anti-inflammatory and anti-oxidative effects [6]. However, little is known for the effects of DHA and EPA on DCM. To date, there has been only one study reporting that DHA protected against palmitate-induced mitochondrial dysfunction in DCM [7]. Thus, the effects of DHA and EPA on DCM warrants more investigation.

Krill oil (KO), extracted from the Euphausia superba (Antarctic krill), is an alternative source of marine omega-3 fatty acids [8]. $\mathrm{KO}$ is rich in DHA, EPA and astaxanthin [9]. Notably, the DHA and EPA found in KO are mainly in the form of phospholipids, which are more beneficial compared with the triacylglycerol form [10]. Astaxanthin has antiinflammatory and anti-oxidative effects, protecting against DM and complications, such as diabetic retinopathy, nephropathy, neuropathy and atherosclerosis [11]. Given the antiinflammatory and anti-oxidative effects of its major components, $\mathrm{KO}$ has potential for prevention of DCM. However, the effect of KO on DCM and the underlying mechanism remain unknown. In the present study, we hypothesize that $\mathrm{KO}$ could prevent the pathological injuries of DCM possibly through its anti-inflammatory or antioxidant activities. Therefore, $\mathrm{KO}$ is evaluated for its effect on DCM using a mouse model of T2DM.

\section{Materials and Methods}

\subsection{Animals Housing and Experiments}

C57BL/ 6 male mice were purchased from Charles River Laboratories (Beijing, China) and were housed in the Animal Center of Shandong University at $22{ }^{\circ} \mathrm{C}$, on a $12: 12 \mathrm{~h}$ lightdark cycle, with free access to a standard AIN-93G diet and tap water. The Institutional Animal Care and Use Committee at Shandong University approved all the experimental procedures (permission number: SYKX20200022).

DM was induced in 8 week old mice by intraperitoneal injection with streptozotocin (STZ, Sigma-Aldrich, Shanghai, China) at $50 \mathrm{mg} / \mathrm{kg} /$ body weight (BW) per day, for 5 consecutive days. One week after the last injection, mice with fasting ( $6 \mathrm{~h}$ fast) blood glucose levels above $13.89 \mathrm{mmol} / \mathrm{L}$ were considered diabetic [12,13]. The nondiabetic control mice (8-week old) were intraperitoneally injected with sodium citrate ( $\mathrm{pH} 4.5)$ as the vehicle for STZ. After the confirmation of DM, the diabetic mice were immediately fed either a high-fat diet or a 1.5\% KO-containing high-fat diet (the ingredients of experimental diets are shown in Supplementary Table S1). The average food intake of mice in the KOtreated group is approximately $2.79 \mathrm{~g} / \mathrm{d}$ (Supplementary Figure S1A), delivering a dose of $\mathrm{KO}$ equivalent to $7 \mathrm{~g} / \mathrm{d}$ for a $60 \mathrm{~kg}$ adult according to the body surface area normalization method [14]. KO was provided by Qingdao Antarctic Weikang Biotechnology Co., Ltd. (Qingdao, China). The composition analysis of KO is summarized in Supplementary Table S2. The non-diabetic control mice continuously received the standard AIN-93G diet.

For all the mice, body weight and food intake were recorded every 2 days post DM onset. Blood glucose levels were determined every 4 weeks post DM onset. By the end of the 22nd week post DM, glucose tolerance test (GTT) was performed. After 24 weeks of $\mathrm{DM}$, the mice were euthanized under an aesthesia by intraperitoneal injection of chloral hydrate $(0.3 \mathrm{mg} / \mathrm{kg})$, with their hearts harvested for analysis.

\subsection{Glucose Tolerance Test (GTT)}

After a $12 \mathrm{~h}$ fast, the mice were intraperitoneally injected with glucose at a dose of $2 \mathrm{~g} / \mathrm{kg} / \mathrm{BW}$. Blood glucose levels were recorded at $0,30,60$ and $120 \mathrm{~min}$ post the injection.

\subsection{Assessment of Cardiac Pathology}

After harvesting, the heart tissues were fixed into a $10 \%$ buffered formalin solution and embedded in paraffin, followed by sectioning into $5 \mu \mathrm{m}$ thick sections onto glass slides. Hematoxylin and eosin (H\&E) staining (ThermoFisher Scientific, Shanghai, China) was performed to evaluate cardiac histology and inflammatory cell infiltration. 
Terminal deoxynucleotidyl transferase dUTP nick-end label (TUNEL) staining (KeyGEN BioTECH, Nanjing, China) was performed to detect cardiomyocyte apoptosis. Masson's trichrome staining (Solarbio, Beijing, China) was used for the evaluation of cardiac fibrosis. The infiltration of inflammatory cells, TUNEL positive cells and Masson's positive area were quantified using Image J software (National Institutes of Health, Bethesda, MD, USA). The selection of areas to photograph and scoring was conducted by people blind to the identity of the samples.

\subsection{RNA Isolation and Quantitative Real-Time Polymerase Chain Reaction (qRT-PCR) Analysis}

For the determination of mRNA levels, total RNA was extracted from the heart tissue using an RNAeasy ${ }^{\mathrm{TM}}$ Animal RNA Isolation Kit (Beyotime, Shanghai, China). RNA concentration and purity were measured using Nanodrop 2000c (ThermoFisher Scientific). The total RNA was reverse transcribed into complementary DNA using a PrimeScript RT reagent Kit (Takara Biomedical Technology, Beijing, China). qRT-PCR was carried out in a $20 \mu \mathrm{L}$ reaction volume containing $10 \mu \mathrm{L}$ LightCycler 480 SYBR Green I Master (Roche, Shanghai, China), $1 \mu \mathrm{L}$ forward primer, $1 \mu \mathrm{L}$ reverse primer, $2 \mu \mathrm{L}$ cDNA and $6 \mu \mathrm{L}$ RNase Free $\mathrm{dH}_{2} \mathrm{O}$. A PCR was carried out in LightCycler 480II Real-Time PCR system (Roche). The fluorescence intensity of each sample was measured at each temperature change to monitor amplification of the genes. The comparative cycle time (CT) was used to determine fold differences between the samples. Levels of the housekeeping gene acidic ribosomal phosphoprotein P0 (Rplp0, also known as 36b4) were used as an internal control for the normalization of RNA quantity and quality differences among the samples. Fold change

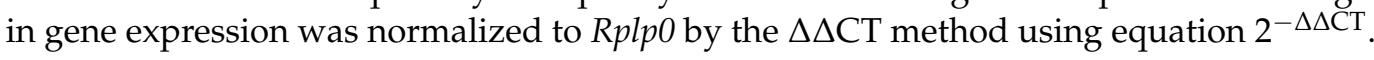
The results were presented as fold changes compared with the control group. The primers for actin alpha 2 (Act $\alpha 2), R p l p 0, \mathrm{C}-\mathrm{C}$ motif chemokine ligand 2 ( $\mathrm{Ccl} 2)$, collagen type I alpha 1 (Col1 $\alpha 1)$, gasdermin D (Gsdmd), intercellular adhesion molecule 1 (Icam1), interferon gamma $(\mathrm{Ifn}-\gamma)$, interleukin 1 beta (Il-1 $\beta)$, NADPH oxidase 4 (Nox4), selectin E (Sele), sirtuin 3 (Sirt3) and tumor necrosis factor alpha $(\operatorname{Tnf}-\alpha)$ were synthesized at Sangon Biotech (Shanghai, China). The sequences of the primers are listed in Table S3.

\subsection{Western Blot Analysis}

To measure protein levels, cardiac tissue was homogenized in a lysis buffer (Beyotime). Western blot analysis was carried out as previously described [15]. Briefly, a bicinchoninic acid assay (Thermofisher Scientific) was used for the determination of the protein concentration. A standard curve was constructed by determining the absorbance of bovine serum albumin with concentrations of $0,0.025,0.125,0.5,0.75,1$ and $1.5 \mathrm{mg} / \mathrm{mL}$. For the measurement of the absorbance of the protein samples, after adding $200 \mu \mathrm{L}$ of working solution to each well of a 96-well plate, $25 \mu \mathrm{L}$ of the protein sample was added to each well, and the absorbance was measured at $562 \mathrm{~nm}$ after incubation at $37^{\circ} \mathrm{C}$ for $30 \mathrm{~min}$. The protein concentration was then calculated using the standard curve. The primary antibodies used were apoptosis-associated speck-like protein containing a CARD (ASC, 1:1000, Cell Signaling Technology, Shanghai, China), $\beta$-tubulin (1:1000, Proteintech, Wuhan, China), Caspase-1 (1:1000, AdipoGen Life Sciences, Beijing, China), collagen type III alpha 1 (COL3A1, 1:1000, Santa Cruz Biotechnology, Shanghai, China), gasdermin D (GSDMD, 1:1000, Cell Signaling Technology), inducible nitric oxide synthase (iNOS, 1:1000, Cell Signaling Technology), IL-1 $\beta$ (1:1000, Cell Signaling Technology), NLR family pyrin domain containing 3 (NLRP3, 1:1000, Cell Signaling Technology) and peroxisome proliferator-activated receptor- $\gamma$ coactivator $1 \alpha$ (PGC-1 $\alpha$, 1:1000, Affinity Biosciences Ltd., Shanghai, China). Western blot images were quantified utilizing Image StudioTM Lite software (LI-COR, Lincoln, NE, USA).

\subsection{Immunohistochemical Staining}

To determine cardiac protein expression and localization, the tissue sections were deparaffinized and rehydrated. Endogenous peroxidase was inactivated by $3 \%$ hydrogen peroxide. Antigens were retrieved using citrate buffer $(0.01 \mathrm{M}, \mathrm{pH} 6.0)$ at $100{ }^{\circ} \mathrm{C}$ for 
3 min. After blocking with 5\% BSA, the sections were incubated with antibodies against alpha-smooth muscle actin ( $\alpha$-SMA, 1:100, Santa Cruz Biotechnology), COL1A1 (1:100, Santa Cruz Biotechnology), 8-hydroxy-2'-deoxyguanosine (8-OHdG, 1:100, Santa Cruz Biotechnology) or PGC-1 $\alpha$ (1:100, Affinity Biosciences Ltd.) at $4{ }^{\circ} \mathrm{C}$ overnight. Following incubation with a secondary antibody at $37^{\circ} \mathrm{C}$ for $1 \mathrm{~h}$, color was developed with a DAB Horseradish Peroxidase Color Development Kit (BOSTER Biological Technology, Wuhan, China), followed by counterstaining with hematoxylin.

\subsection{Statistical Analysis}

Eight mice per group were studied. The data were expressed as the means \pm standard deviation. All the assays were conducted in triplicate. The data were analyzed using one-way analysis of variance (SPSS 19.0). The difference between groups were assessed by the least significant difference (LSD). $p<0.05$ was considered statistically significant.

\section{Results}

\subsection{KO Alleviated the DM-Induced Cardiac Pathological Injuries}

To investigate the effect of KO on DM-induced cardiac pathological injuries, C57BL/ 6 mice were induced to DM and were treated with $\mathrm{KO}$ for 24 weeks. Blood glucose levels were elevated in the diabetic mice and were not affected by $\mathrm{KO}$ (Figure 1A). In consistence, KO did not improve the DM-induced glucose intolerance (Figure 1B,C). Body weight, heartweight-to-body-weight ratio and heart-weight-to-tibia-length ratio were not affected by $\mathrm{KO}$ (Supplementary Figure S1B-D). The diabetic mice had increased infiltration of inflammatory cells into the paravascular spaces (Figure 1D,E), and developed cardiomyocyte hypertrophy (Figure 1D). These effects were remarkably inhibited by KO (Figure 1D,E). Moreover, KO significantly reduced the DM-enhanced accumulation of cardiac fibrosis (Figure $1 \mathrm{~F}, \mathrm{G}$ ) and apoptotic cell death (Figure 1H,I).

\subsection{KO Prevented the DM-Induced Cardiac Expression of Profibrotic Genes}

Since the DM-induced cardiac fibrosis was inhibited by $\mathrm{KO}, \mathrm{KO}$ was tested for its effect on cardiac profibrotic gene expression. The diabetic mice had increased cardiac expression of Act 2 and Col1 $\alpha 1$ mRNAs (Figure 2A,B), and COL3A1 protein (Figure 2C). IHC staining revealed increased $\alpha$-SMA and COL1A1 positive areas in the diabetic heart (Figure 2D,E). These effects were markedly prevented by KO (Figure 2A-E).

\subsection{KO Attenuated the DM-Generated Cardiac Oxidative Stress}

To assess the effect of $\mathrm{KO}$ on cardiac oxidative stress, the mRNA levels of Nox4 (Figure 3A), protein levels of iNOS (Figure 3B), positive stain of DHE (Figure 3C) and 8-OHdG (Figure 3D) were determined. All these oxidative markers were elevated in the $\mathrm{DM}$ group and were decreased in the presence of $\mathrm{KO}$ (Figure 3A-D). 
A

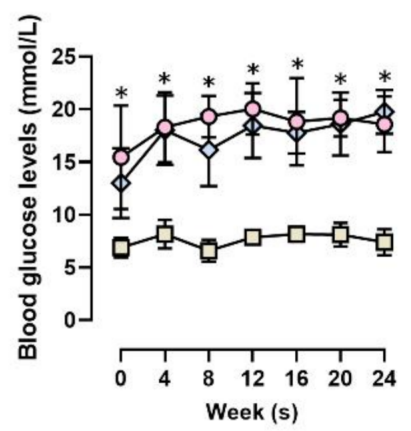

D

$\underset{\Upsilon}{\varpi}$ Ctrl DM B

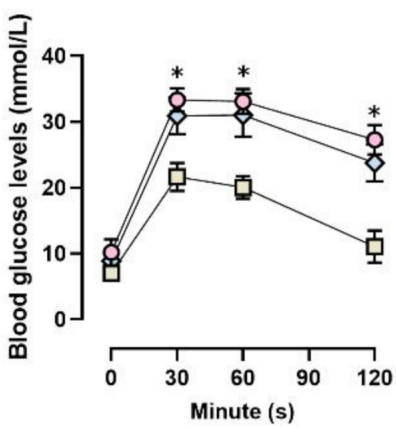

DM/KO

王

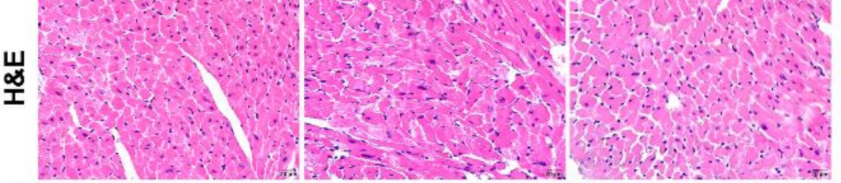

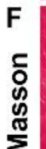
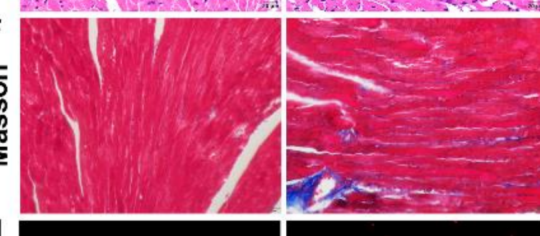

H

$H$
픈

这
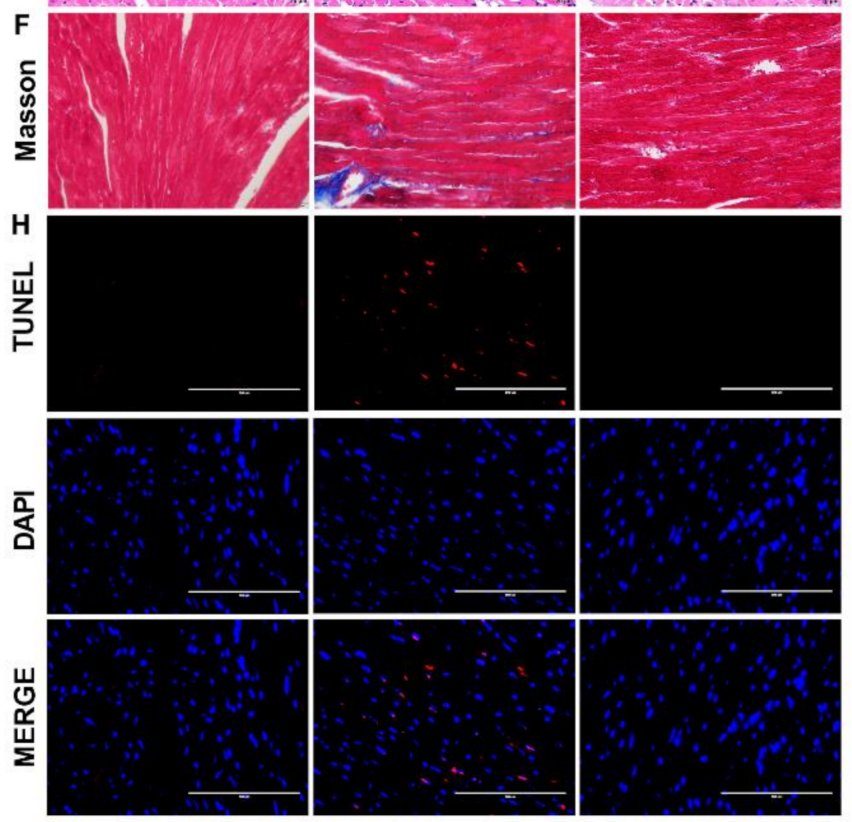

C

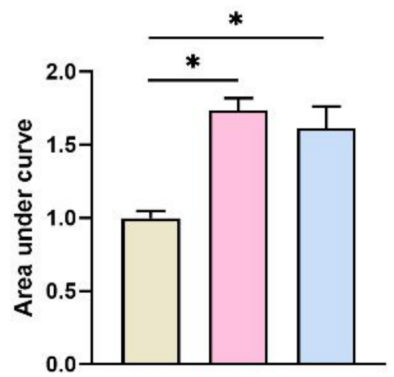

ㅁ Ctrl $\square$ Ctrl

- D DM 口 DM

$\diamond \mathrm{DM} / \mathrm{KO} \quad \square \mathrm{DM} / \mathrm{KO}$

E

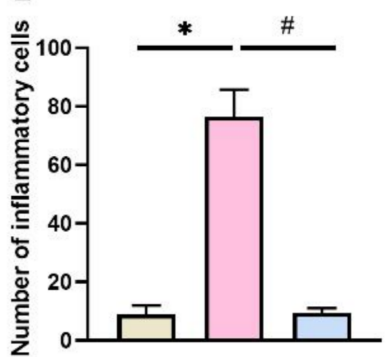

G
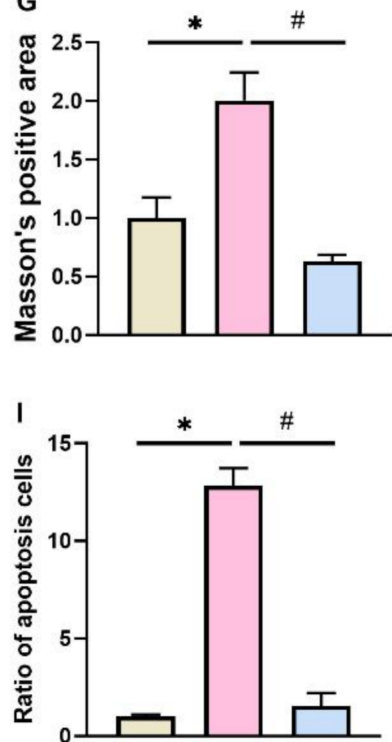

Figure 1. KO alleviated the DM-induced cardiac pathological injuries. (A) Blood glucose levels of C57BL $/ 6$ male mice were recorded every 4 weeks post diabetes mellitus (DM) onset. (B) Glucose tolerance test was performed 22 weeks post DM onset, with (C) the areas under the curve quantified. (D) Hematoxylin and eosin $(\mathbf{E}, \mathbf{H})$ staining with $(\mathbf{E})$ the number of inflammatory cells infiltrated per vessel quantified ( $\mathrm{Bar}=20 \mu \mathrm{m}$ ). (F) Masson's trichrome staining with $(\mathbf{G})$ the positive area quantified $(B a r=20 \mu \mathrm{m})$. (H) TUNEL staining with (I) the ratio of apoptosis cells quantified (Bar $=100 \mu \mathrm{m})$. The data were normalized to $C$ trl and summarized as means $\pm \mathrm{SD}$. ${ }^{*}, p<0.05$ vs. Ctrl; $\#, p<0.05$ vs. DM. Abbreviations, Ctrl, control; DM, diabetes mellitus; H\&E, hematoxylin and eosin; KO, krill oil; TUNEL, terminal deoxynucleotidyl transferase dUTP nick-end label. 
A

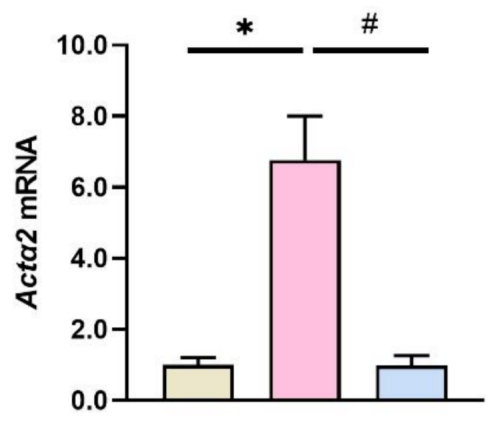

C

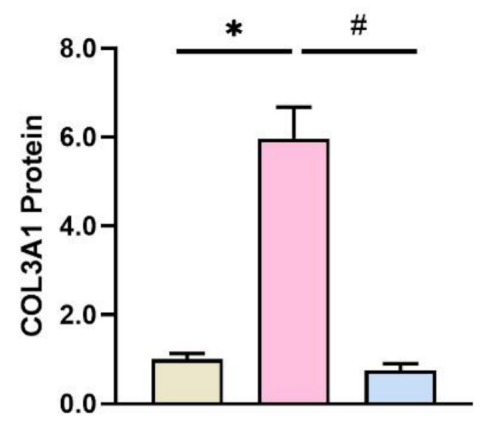

B

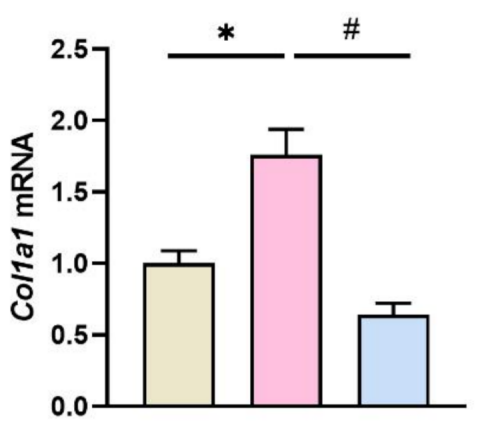

D

Ctrl

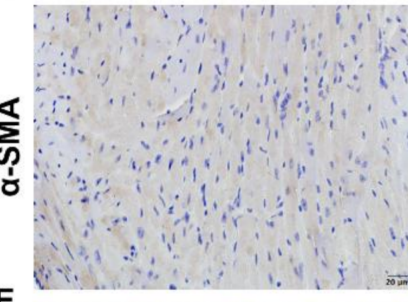

E

$\frac{1}{0}$
DM

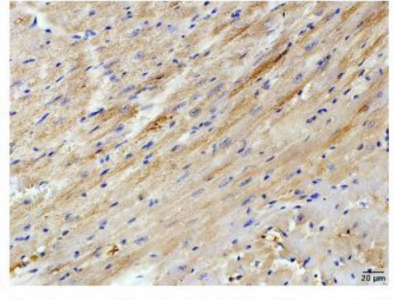

$\mathrm{DM} / \mathrm{KO}$
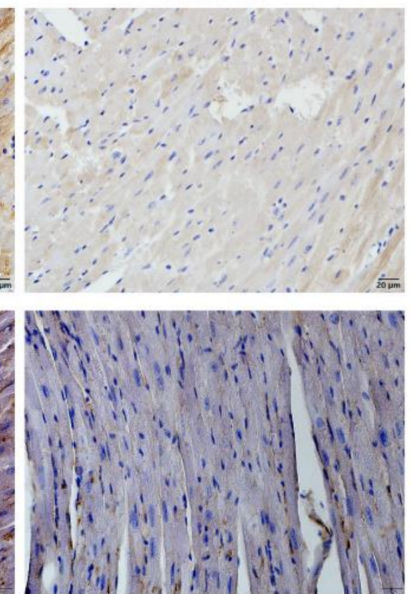

Figure 2. KO prevented the DM-induced cardiac expression of profibrotic genes. Cardiac mRNA expression of (A) Act $\alpha 2$ and (B) Col1 1 were determined by qRT-PCR. Cardiac protein expression of (C) COL3A1 was determined by Western blot and (D) $\alpha$-SMA and (E) COL1A1 were detected by Immunohistochemical staining ( $\mathrm{Bar}=20 \mu \mathrm{m}$ ). Tubulin and Rplp0 (also known as 36b4) were used as endogenous controls for Western blot and qRT-PCR, respectively. The data were normalized to Ctrl and summarized as means \pm SD. ${ }^{*}, p<0.05$ vs. Ctrl; $\#, p<0.05$ vs. DM. Abbreviations: $\alpha$-SMA, alpha-smooth muscle actin; Acta2, actin alpha 2; Col1 $\alpha 1$, collagen 1 alpha 1; COL3A1, collagen 3 alpha 1; Rplp0, acidic ribosomal phosphoprotein P0. Other abbreviations are the same as Figure 1. 
A

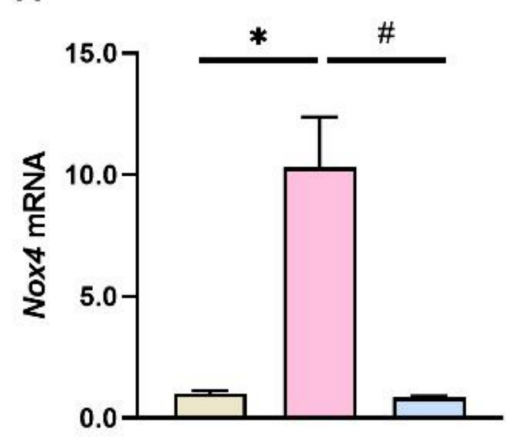

C

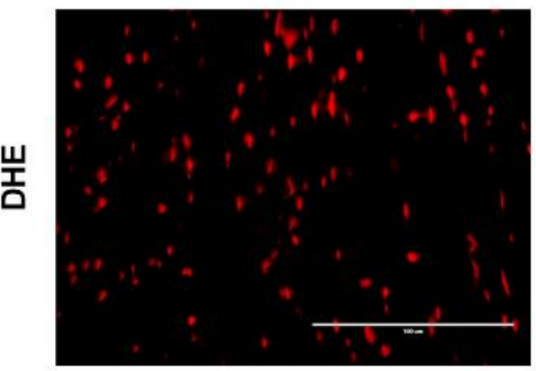

D

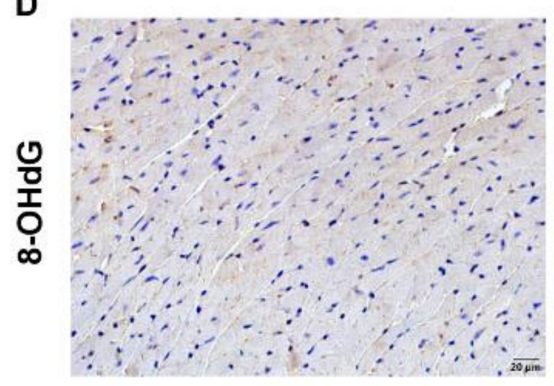

B

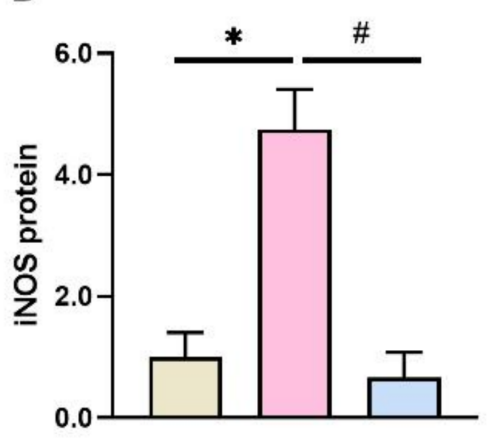

$\square$ Ctrl

$\square$ DM

$\square$ DM/KO

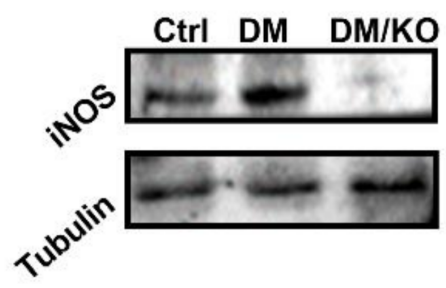

DM/KO
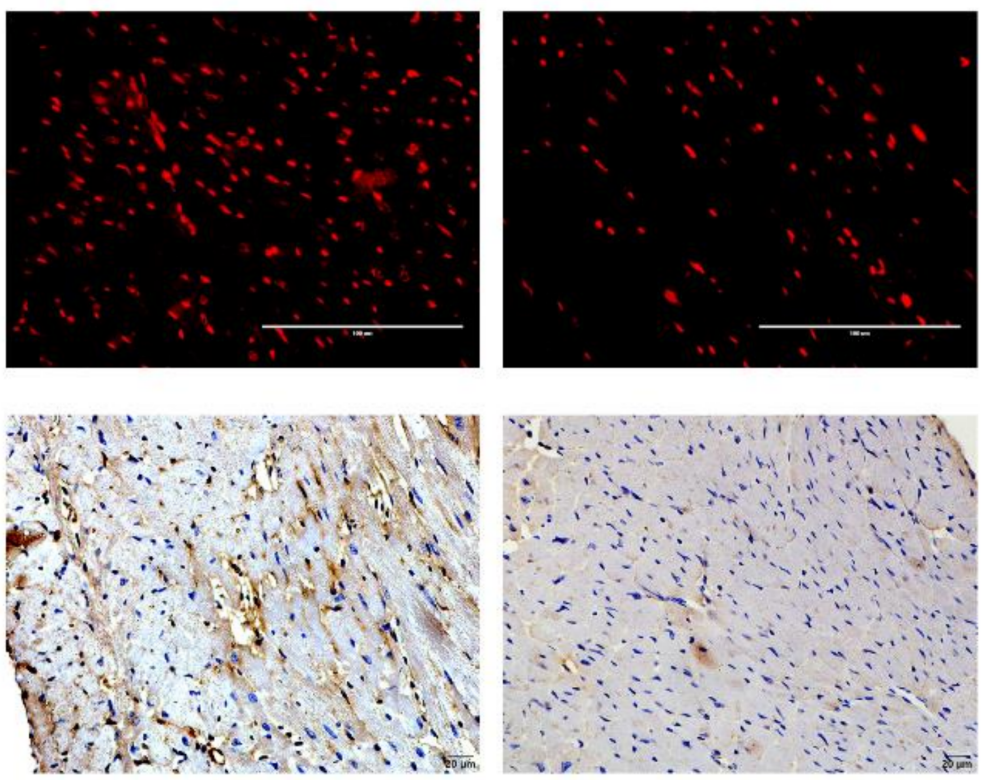

Figure 3. KO attenuated the DM-generated cardiac oxidative stress. (A) Nox4 mRNA levels. (B) iNOS protein levels. Tubulin and Rplp0 were used as endogenous controls for Western blot and qRT-PCR, respectively. (C) Representative microphotographs of DHE staining in heart sections in each group $($ Bar $=100 \mu \mathrm{m})$. (D) Immunohistochemical staining showed expression of 8-OHdG $($ Bar $=20 \mu \mathrm{m})$. The data were normalized to Ctrl and summarized as means $\pm \mathrm{SD} .{ }^{*}, p<0.05$ vs. Ctrl; $\#, p<0.05$ vs. DM. Abbreviations: DHE, dihydroethidium; Nox4, NADPH oxidase 4; iNOS, inducible nitric oxide synthase; 8-OHdG, 8-hydroxy-2 deoxyguanosine. Other abbreviations are the same as Figures 1 and 2.

\subsection{KO Ameliorated the DM-Promoted Proinflammatory Gene Transcription}

Based on the KO-reduced infiltration of inflammatory cells in the hearts of the diabetic mice (Figure 1D), KO was further evaluated for its effect on the transcription of proinflammatory genes. The diabetic mice had increased mRNA levels of Tnf- $\alpha$ (Figure 4A), Ifn- $\gamma$ (Figure 4B), Icam1 (Figure 4C), Sele (Figure 4D), Ccl2 (Figure 4E) and Il-1 (Figure 4F), all of which were significantly decreased by KO. 
A

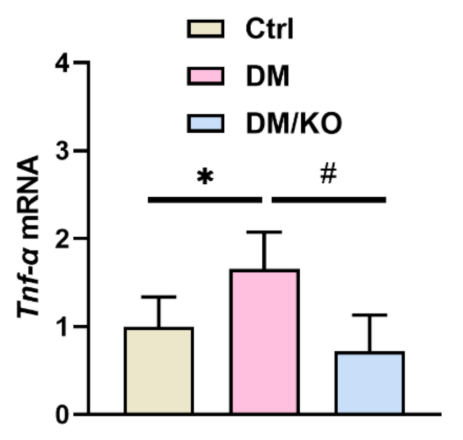

C

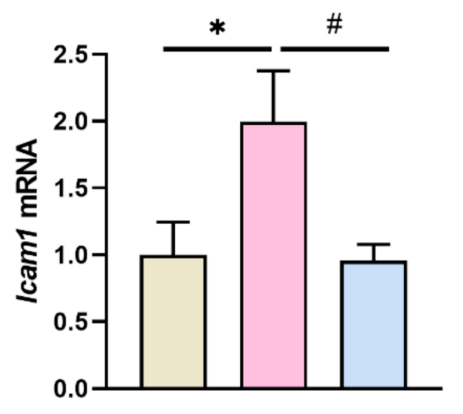

E

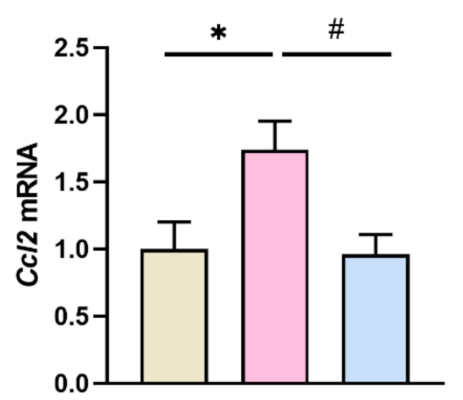

B

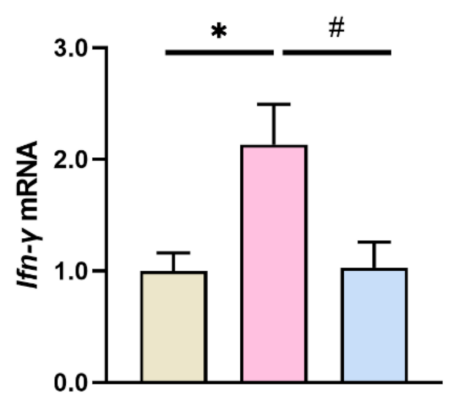

D

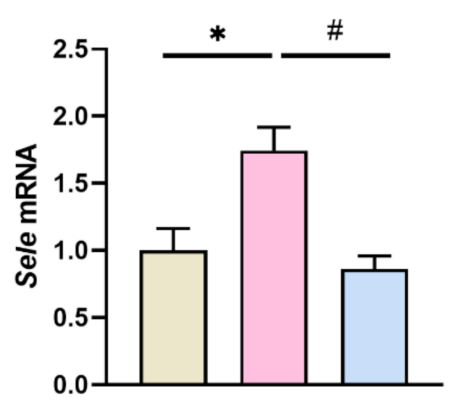

$\mathbf{F}$

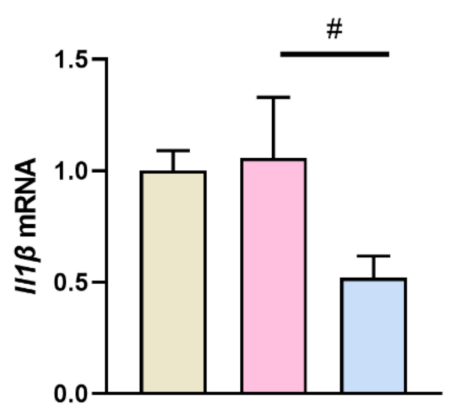

Figure 4. KO ameliorated the DM-promoted proinflammatory gene transcription. Cardiac mRNA expression of (A) Tnf- $\alpha$, (B) Ifn- $\gamma$, (C) Icam1, (D) Sele, (E) Ccl2, and (F) Il-1 $\beta$ were determined by qRTPCR. Rplp0 was used as an endogenous control. The data were normalized to Ctrl and summarized as means \pm SD. ${ }^{*}, p<0.05$ vs. Ctrl; \#, $p<0.05$ vs. DM. Abbreviations: Ccl2, C $-\mathrm{C}$ motif chemokine ligand 2; Icam1, intercellular adhesion molecule 1 ; Ifn- $\gamma$, interferon gamma; Il-1 $\beta$, interleukin 1beta; Sele, selectin; Tnf- $\alpha$, tumor necrosis factor alpha. Other abbreviations are the same as Figures 1 and 2.

\subsection{KO Drastically Inhibited NLRP3 Inflammasome Activation in the Diabetic Hearts}

To further investigate the mechanism by which $\mathrm{KO}$ markedly inhibited cardiac proinflammatory gene transcription in the diabetic mice (Figure $4 \mathrm{~A}-\mathrm{F}$ ), the protein levels of NLRP3 inflammasome components-NLRP3 (Figure 5A), cleaved caspase-1 (Figure 5B), ASC (Figure 5C) and cleaved IL-1 $\beta$ (Figure 5D)—were measured. All these proteins were increased in the DM group and were dramatically reduced by KO (Figure 5A-D). As cleavage of GSDMD is induced by cleaved caspase-1, leading to pyroptosis in DCM [16], we further determined the protein levels of cleaved GSDMD (Figure 5E) and mRNA levels of 
Gsdmd (Figure 5F), both of which were increased in the diabetic hearts and were decreased by $\mathrm{KO}$ (Figure $5 \mathrm{E}, \mathrm{F})$.

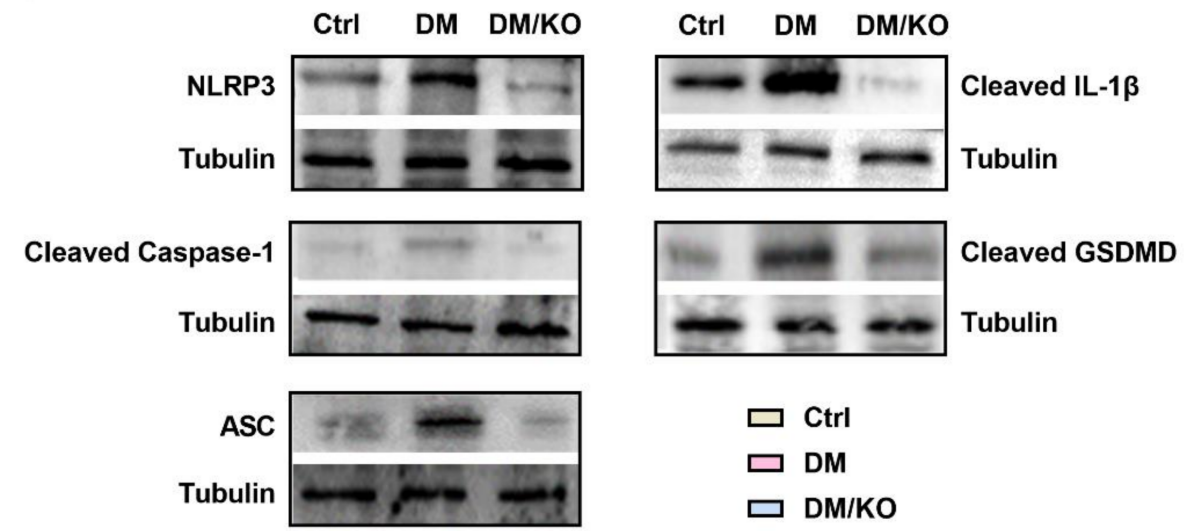

A

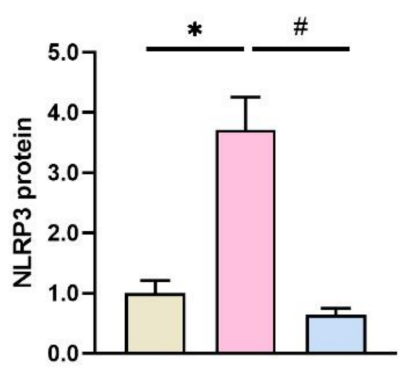

D

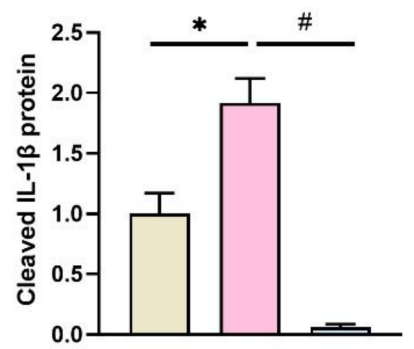

B

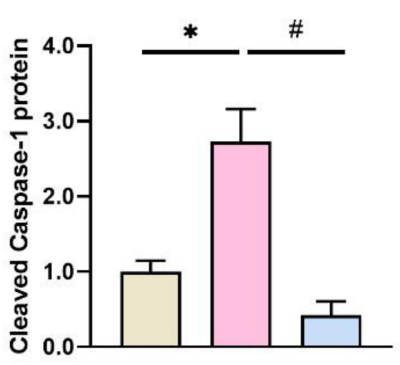

E

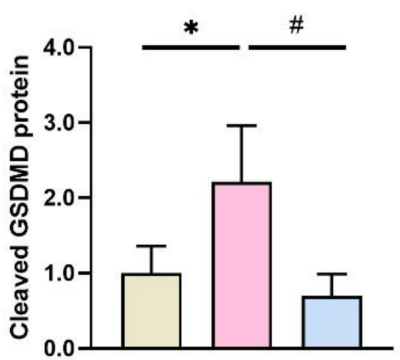

C

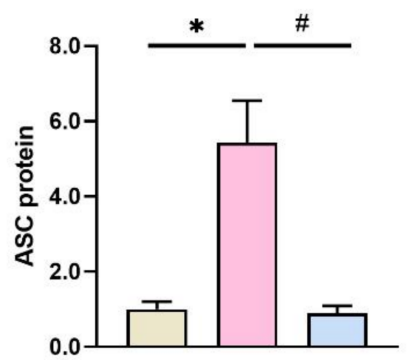

F

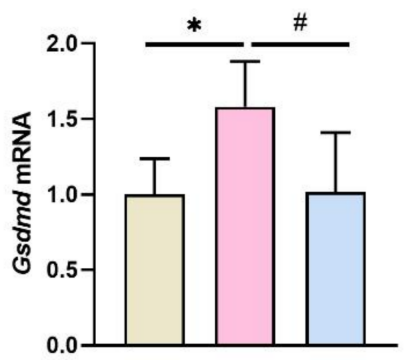

Figure 5. KO drastically inhibited NLRP3 inflammasome activation in the diabetic hearts. Cardiac protein expression of (A) NLRP3, (B) Cleaved caspase-1, (C) ASC, (D) Cleaved IL-1 $\beta$, (E) Cleaved GSDMD were determined by Western Blot. (F) Gsdmd mRNA levels. Tubulin and Rplp0 were used as endogenous controls for Western blot and qRT-PCR, respectively. The data were normalized to Ctrl and summarized as means \pm SD. ${ }^{*}, p<0.05$ vs. Ctrl; $\#, p<0.05$ vs. DM. Abbreviations: ASC, adaptor apoptosis-associated speck-like protein containing a caspase activation and recruitment domain; GSDMD, gasdermin D; NLRP3, Nod-like receptor family, pyrin domain containing 3. Other abbreviations are the same as Figures 1 and 2.

\subsection{KO Activated Cardiac PGC1- $\alpha / S I R T 3$ as the Upstream Regulators of NLRP3}

In order to further explore potential molecular targets of $\mathrm{KO}$, we determined the expression of PGC1- $\alpha$ /SIRT3 that are known as the upstream regulators of NLRP3 in kidneys of the mice. KO significantly increased both mRNA and protein levels of cardiac SIRT3 
(Figure 6A,B) and protein levels of cardiac PGC1- $\alpha$ (Figure 6C) in the diabetic mice. IHC staining further confirmed that PGC1- $\alpha$ protein was reduced in the diabetic cardiomyopathy, whereas KO could increase cardiac PGC1- $\alpha$ protein expression (Figure 6D).

A
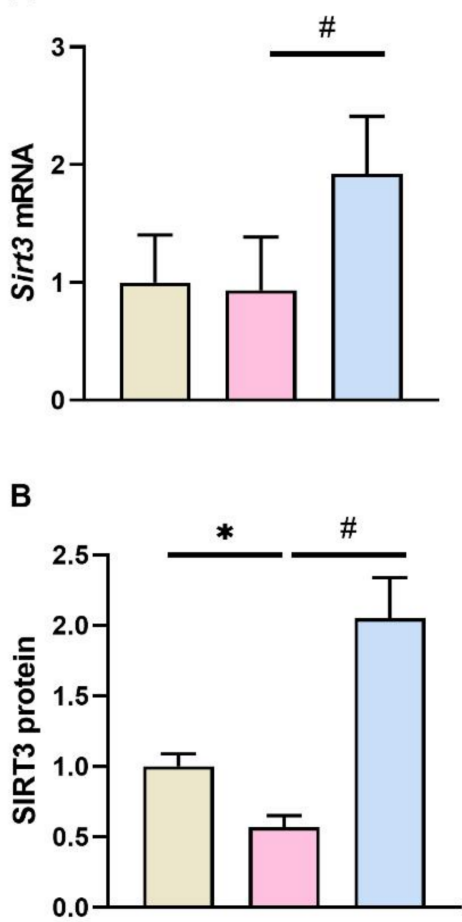

C

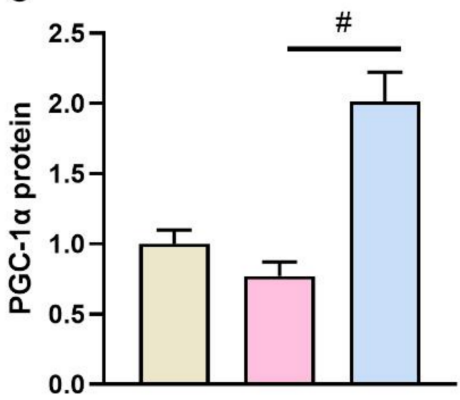

(Ctrl

口 DM

口 DM/KO

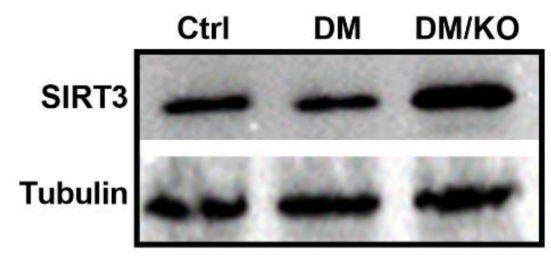

D

Ctrl

DM

DM/KO
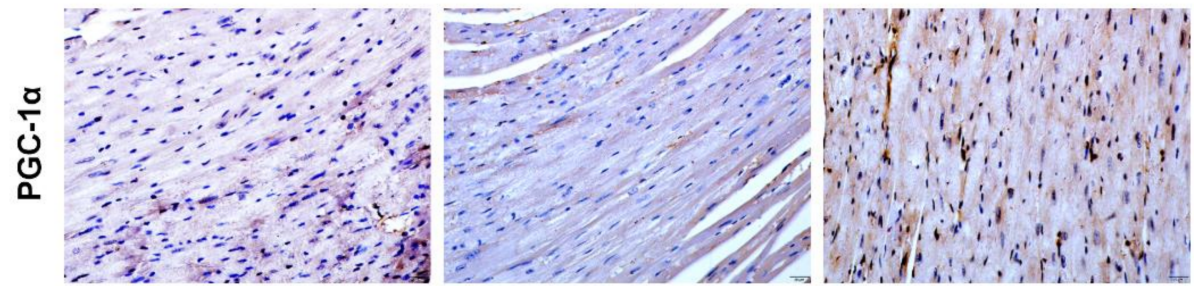

Figure 6. $\mathrm{KO}$ activated cardiac PGC1- $\alpha / \mathrm{SIRT3}$ as the upstream regulators of NLRP3. (A) Sirt3 mRNA levels, (B) SIRT3 protein levels, (C) PGC-1 $\alpha$ protein levels, (D) immunohistochemical staining of cardiac PGC-1 $\alpha$ (Bar $=20 \mu \mathrm{m})$. Tubulin and Rplp0 were used as endogenous controls for Western blot and qRT-PCR, respectively. The data were normalized to Ctrl and summarized as means \pm SD. *, $p<0.05$ vs. Ctrl; \#, $p<0.05$ vs. DM. Abbreviations: PGC- $1 \alpha$, PPARG coactivator 1 alpha; SIRT3, sirtuin 3. Other abbreviations are the same as Figures 1 and 2. 


\section{Discussion}

In the present study, we report the preventive effect of $\mathrm{KO}$ on the pathological injuries of DCM using a mouse model of T2DM. The diabetic mice developed cardiac pathological injuries, inflammation and oxidative stress, the effects of which were prevented by $\mathrm{KO}$. Notably, KO significantly inhibited NLRP3. Further investigation revealed SIRT3/PGC-1 $\alpha$ as potential molecular targets of $\mathrm{KO}$ (Figure 7).

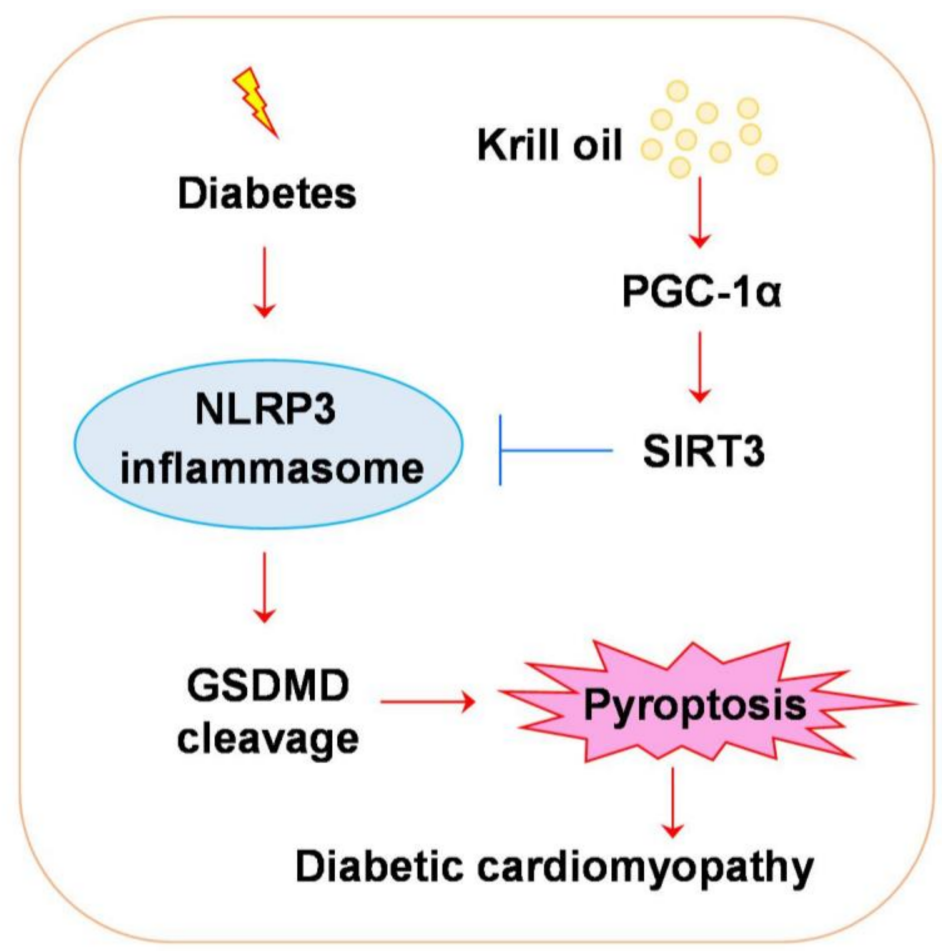

Figure 7. The possible molecular mechanism of $\mathrm{KO}$ in inhibiting pyroptosis in DCM. Under diabetic condition, NLRP3 inflammasome is activated, leading to the cleavage of GSDMD and the following pyroptosis. KO could upregulate the expression of PGC- $1 \alpha$ and SIRT3, which are upstream negative regulators of NLRP3 inflammasome. $\downarrow$, activation; $\perp$, inhibition. Abbreviations: DCM, diabetic cardiomyopathy. Other abbreviations are the same as in Figures 1, 5 and 6.

Accumulation of fibrosis and apoptosis of cardiomyocytes are key pathological features of DCM [17]. In the DM milieu, extracellular matrix proteins are overproduced and form fibrosis in the heart, contributing to cardiac dysfunction $[4,17,18]$. Apoptosis of cardiomyocytes causes a reduction in the cardiomyocyte population, enhancing the burden of viable cardiomyocytes to maintain normal cardiac function. This subsequently enlarges the cells, leading to pathological hypertrophy and the following cardiac dysfunction [19]. Therefore, the inhibition of profibrotic gene expression and cardiomyocyte apoptosis is key to the successful prevention of DCM. In the present work, we observed the potent inhibitory effects of $\mathrm{KO}$ on DM-induced cardiac fibrosis and apoptotic cell death (Figure $1 \mathrm{~F}-\mathrm{I}$ and Figure 2), shedding light on the future clinical prevention of DCM.

Inflammation and oxidative stress cause the generation of fibrosis and apoptosis of cardiomyocytes, thereby playing essential roles in the pathogenesis of DCM [20]. DMinduced cardiac inflammation is driven by NLRP3 inflammasome [21,22], which can be activated by reactive oxygen species (ROS) [23]. Upon various stimuli, including ROS, pro-caspase- 1 is cleaved, resulting in the cleavage of proinflammatory cytokines IL- $1 \beta$ and IL-18, and the protein gasdermin D (GSDMD). The N-terminal domain of GSDMD penetrates pores in the plasma membrane, thereby triggering a lytic, pro-inflammatory form of cell death, namely pyroptosis [16]. Pyroptosis leads to the release of cytokines that, in turn, exacerbate NLRP3-mediated inflammation and facilitate inflammatory cells 
infiltration [24]. In the present study, we found remarkable elevated cardiac oxidative stress and proinflammatory gene transcription in the diabetic mice (Figures 3 and 4). In line with previous reports $[23,25,26]$, NLRP3 was significantly activated in the diabetic hearts (Figure 5A-D). Notably, KO had a striking inhibitory effect on the DM-activated NLRP3 (Figure 5A-D). These data suggest that NLRP3 is an important molecular target of KO.

Recent findings have uncovered important protective roles of SIRT3 and PGC-1 $\alpha$ in DCM [27-29]. SIRT3 belongs to the sirtuin family of proteins, exerting an NAD+-dependent deacetylase activity [30]. Compared with wild-type (WT) diabetic mice, Sirt3 gene knockout diabetic mice developed more severe DM-induced cardiac injuries [27]. The activation of SIRT3 by polydatin, icariin and salidroside attenuated DCM in WT diabetic mice [27,29,31]. SIRT3 deacetylase activity is required for the protein stability of PGC-1 $\alpha$ [32] - a member of a family of transcription coactivators that plays a central role in the regulation of cellular energy metabolism [33]. PGC-1 $\alpha$, in turn, activates SIRT3 [34,35], and is protective in DCM pathogenesis [36-39]. Collectively, these studies have demonstrated a positive feedback interaction between SIRT3 and PGC- $1 \alpha$, providing SIRT3/PGC- $1 \alpha$ activation as a viable strategy for the intervention of DCM. Moreover, SIRT3 has been reported to be a crucial negative regulator of NLRP3 [40-43]. Mechanistically, SIRT3 deacetylates SOD2, leading to SOD2 activation, which impairs NLRP3 inflammasome assembly and activation [41]. The present study found that KO upregulated the protein levels SIRT3 and PGC-1 $\alpha$ (Figure 6), the effects of which were in accordance with KO's inhibitory effect on NLRP3. Thus, KO might inhibit NLRP3 via the upregulation of SIRT3/PGC-1 $\alpha$ in DCM. The identification of PGC- $1 \alpha$ and SIRT3 in addition to NLRP3 provided more viable molecular targets of KO in the prevention of DCM. Although KO is known to have inflammatory efficacies, its effect on NLRP3, SIRT3 and PGC-1 $\alpha$ is not previously reported. To date, this has been the first study to report KO's effect on SIRT3/PGC-1 $\alpha /$ NLRP3. Given that SIRT3, PGC- $1 \alpha$ and NLRP3 play important roles in various diseases, the findings in our study might indicate SIRT3, PGC-1 $\alpha$ and NLRP3 as potential mechanisms through which KO benefits diseases.

In human studies, $\mathrm{KO}$ has proven beneficial for a few diseases, including osteoarthritis, arthritis, knee joint pain and hyperlipidemia [44], all of which are closely associated with inflammation and oxidative stress. To date, $\mathrm{KO}$ has not been investigated for its effects on clinical DM and complications. The potent inhibitory effects of KO on DM-induced cardiac inflammation holds promise for future clinical intervention of DM and complications, including DCM. Additionally, the present work might indicate that functional lipids containing bioactive components, such as KO, hazelnut oil [45], among others, warrant more attention in the future intervention of diseases.

\section{Conclusions}

The present study reports for the first time the preventive effect of $\mathrm{KO}$ on the pathological injuries of DCM. In addition, SIRT3, PGC- $1 \alpha$ and NLRP3 were identified as molecular targets of $\mathrm{KO}$. Our work presents $\mathrm{KO}$ supplementation as a viable approach in the clinical intervention of DCM.

Supplementary Materials: The following are available online at https: / www.mdpi.com/article / 10.3390/nu14020368/s1. Table S1: The composition of ingredients of experimental diets; Table S2: Composition analysis of the krill oil used in the study; Table S3: Sequences of primers used for qRT-PCR; Figure S1: Basic data for animal models. (A) Average food intake. (B) Body weight. After harvesting, the hearts were weighed, with ratios of $(C)$ heart to body weight, and (D) heart weight to tibia length calculated. For $(C, D)$, the data were normalized to Ctrl and summarized as means $\pm S D$. *, $p<0.05$ vs. Ctrl; Abbreviations: Ctrl, control; DM, diabetes mellitus; KO, krill oil.

Author Contributions: H.W. and L.D. designed the project. X.S. (Xuechun Sun), Xiaodan Sun, H.M., J.W. and X.G. researched the data. H.W. and X.S. (Xuechun Sun) wrote the manuscript. X.S. (Xuechun Sun), X.S. (Xiaodan Sun), H.M., J.W., X.G. and L.D. revised the manuscript. All authors have read and agreed to the published version of the manuscript. 
Funding: This work was supported in part by National Natural Science Foundation of China (81973031) and Cheeloo Young Scholar Program of Shandong University (21320089963054) to H.W.; National Natural Science Foundation of China (82003447), Young Scholars Program of Shandong University (2018WLJH34) and the Laboratory for Marine Drugs and Bioproducts of Qingdao National Laboratory for Marine Science and Technology (LMDBKF-2019-05) to L.D.; and National Natural Science Foundation of China (81803224) and Young Scholars Program of Shandong University (2018WLJH33) to X.G.

Institutional Review Board Statement: All experimental procedures were performed according to the Laboratory Animal Welfare Standards and approved by the Subcommittee of Experimental Animal Ethics, Shandong University (Permission number: SYKX20200022).

Informed Consent Statement: Not applicable.

Data Availability Statement: The datasets used and/or analyzed during the current study are available from the corresponding author on reasonable request.

Conflicts of Interest: There is no conflict of interest to declare.

\section{References}

1. Saeedi, P.; Petersohn, I.; Salpea, P.; Malanda, B.; Karuranga, S.; Unwin, N.; Colagiuri, S.; Guariguata, L.; Motala, A.A.; Ogurtsova, K.; et al. Global and regional diabetes prevalence estimates for 2019 and projections for 2030 and 2045: Results from the International Diabetes Federation Diabetes Atlas, 9(th) edition. Diabetes Res. Clin. Pract. 2019, 157, 107843. [CrossRef] [PubMed]

2. Huynh, K.; Bernardo, B.C.; McMullen, J.R.; Ritchie, R.H. Diabetic cardiomyopathy: Mechanisms and new treatment strategies targeting antioxidant signaling pathways. Pharmacol. Ther. 2014, 142, 375-415. [CrossRef] [PubMed]

3. Klajda, M.D.; Scott, C.G.; Rodeheffer, R.J.; Chen, H.H. Diabetes Mellitus Is an Independent Predictor for the Development of Heart Failure: A Population Study. Mayo Clin. Proc. 2020, 95, 124-133. [CrossRef] [PubMed]

4. Tate, M.; Grieve, D.J.; Ritchie, R.H. Are targeted therapies for diabetic cardiomyopathy on the horizon? Clin. Sci. 2017, 131, 897-915. [CrossRef]

5. Ritchie, R.H.; Abel, E.D. Basic Mechanisms of Diabetic Heart Disease. Circ. Res. 2020, 126, 1501-1525. [CrossRef] [PubMed]

6. Zaloga, G.P. Narrative Review of n-3 Polyunsaturated Fatty Acid Supplementation upon Immune Functions, Resolution Molecules and Lipid Peroxidation. Nutrients 2021, 13, 662. [CrossRef]

7. Gui, T.; Li, Y.; Zhang, S.; Zhang, N.; Sun, Y.; Liu, F.; Chen, Q.; Gai, Z. Docosahexaenoic acid protects against palmitate-induced mitochondrial dysfunction in diabetic cardiomyopathy. Biomed. Pharmacother. 2020, 128, 110306. [CrossRef] [PubMed]

8. Burri, L.; Johnsen, L. Krill products: An overview of animal studies. Nutrients 2015, 7, 3300-3321. [CrossRef]

9. Song, G.; Wang, H.; Zhang, M.; Zhang, Y.; Wang, H.; Yu, X.; Wang, J.; Shen, Q. Real-Time Monitoring of the Oxidation Characteristics of Antarctic Krill Oil (Euphausia superba) during Storage by Electric Soldering Iron Ionization Mass SpectrometryBased Lipidomics. J. Agric. Food Chem. 2020, 68, 1457-1467. [CrossRef] [PubMed]

10. Liu, L.; Bartke, N.; Van Daele, H.; Lawrence, P.; Qin, X.; Park, H.G.; Kothapalli, K.; Windust, A.; Bindels, J.; Wang, Z.; et al. Higher efficacy of dietary DHA provided as a phospholipid than as a triglyceride for brain DHA accretion in neonatal piglets. J. Lipid Res. 2014, 55, 531-539. [CrossRef]

11. Landon, R.; Gueguen, V.; Petite, H.; Letourneur, D.; Pavon-Djavid, G.; Anagnostou, F. Impact of Astaxanthin on Diabetes Pathogenesis and Chronic Complications. Mar. Drugs 2020, 18, 357. [CrossRef] [PubMed]

12. Guo, W.; Tian, D.; Jia, Y.; Huang, W.; Jiang, M.; Wang, J.; Sun, W.; Wu, H. MDM2 controls NRF2 antioxidant activity in prevention of diabetic kidney disease. Biochim. Biophys. Acta Mol. Cell Res. 2018, 1865, 1034-1045. [CrossRef] [PubMed]

13. Wu, H.; Kong, L.; Tan, Y.; Epstein, P.N.; Zeng, J.; Gu, J.; Liang, G.; Kong, M.; Chen, X.; Miao, L.; et al. C66 ameliorates diabetic nephropathy in mice by both upregulating NRF2 function via increase in miR-200a and inhibiting miR-21. Diabetologia 2016, 59, 1558-1568. [CrossRef]

14. Reagan-Shaw, S.; Nihal, M.; Ahmad, N. Dose translation from animal to human studies revisited. FASEB J. 2008, $22,659-661$. [CrossRef]

15. Wu, H.; Zhou, S.; Kong, L.; Chen, J.; Feng, W.; Cai, J.; Miao, L.; Tan, Y. Metallothionein deletion exacerbates intermittent hypoxia-induced renal injury in mice. Toxicol. Lett. 2015, 232, 340-348. [CrossRef] [PubMed]

16. Kelley, N.; Jeltema, D.; Duan, Y.; He, Y. The NLRP3 Inflammasome: An Overview of Mechanisms of Activation and Regulation. Int. J. Mol. Sci. 2019, 20, 3328. [CrossRef]

17. Adeghate, E. Molecular and cellular basis of the aetiology and management of diabetic cardiomyopathy: A short review. Mol. Cell. Biochem. 2004, 261, 187-191. [CrossRef] [PubMed]

18. Asbun, J.; Villarreal, F.J. The pathogenesis of myocardial fibrosis in the setting of diabetic cardiomyopathy. J. Am. Coll. Cardiol. 2006, 47, 693-700. [CrossRef] [PubMed]

19. Jubaidi, F.F.; Zainalabidin, S.; Taib, I.S.; Hamid, Z.A.; Budin, S.B. The Potential Role of Flavonoids in Ameliorating Diabetic Cardiomyopathy via Alleviation of Cardiac Oxidative Stress, Inflammation and Apoptosis. Int. J. Mol. Sci. 2021, $22,5094$. [CrossRef] [PubMed] 
20. Varga, Z.V.; Giricz, Z.; Liaudet, L.; Haskó, G.; Ferdinandy, P.; Pacher, P. Interplay of oxidative, nitrosative/nitrative stress, inflammation, cell death and autophagy in diabetic cardiomyopathy. Biochim. Biophys. Acta 2015, 1852, 232-242. [CrossRef] [PubMed]

21. Kaur, N.; Guan, Y.; Raja, R.; Ruiz-Velasco, A.; Liu, W. Mechanisms and Therapeutic Prospects of Diabetic Cardiomyopathy Through the Inflammatory Response. Front. Physiol. 2021, 12, 694864. [CrossRef] [PubMed]

22. Vandanmagsar, B.; Youm, Y.H.; Ravussin, A.; Galgani, J.E.; Stadler, K.; Mynatt, R.L.; Ravussin, E.; Stephens, J.M.; Dixit, V.D. The NLRP3 inflammasome instigates obesity-induced inflammation and insulin resistance. Nat. Med. 2011, 17, 179-188. [CrossRef] [PubMed]

23. Zhang, H.; Chen, X.; Zong, B.; Yuan, H.; Wang, Z.; Wei, Y.; Wang, X.; Liu, G.; Zhang, J.; Li, S.; et al. Gypenosides improve diabetic cardiomyopathy by inhibiting ROS-mediated NLRP3 inflammasome activation. J. Cell. Mol. Med. 2018, 22, 4437-4448. [CrossRef] [PubMed]

24. Fender, A.C.; Kleeschulte, S.; Stolte, S.; Leineweber, K.; Kamler, M.; Bode, J.; Li, N.; Dobrev, D. Thrombin receptor PAR4 drives canonical NLRP3 inflammasome signaling in the heart. Basic Res. Cardiol. 2020, 115, 10. [CrossRef] [PubMed]

25. Che, H.; Wang, Y.; Li, H.; Li, Y.; Sahil, A.; Lv, J.; Liu, Y.; Yang, Z.; Dong, R.; Xue, H.; et al. Melatonin alleviates cardiac fibrosis via inhibiting lncRNA MALAT1/miR-141-mediated NLRP3 inflammasome and TGF- $\beta 1 /$ Smads signaling in diabetic cardiomyopathy. FASEB J. Off. Publ. Fed. Am. Soc. Exp. Biol. 2020, 34, 5282-5298. [CrossRef] [PubMed]

26. Luo, B.; Li, B.; Wang, W.; Liu, X.; Liu, X.; Xia, Y.; Zhang, C.; Zhang, Y.; Zhang, M.; An, F. Rosuvastatin alleviates diabetic cardiomyopathy by inhibiting NLRP3 inflammasome and MAPK pathways in a type 2 diabetes rat model. Cardiovasc. Drugs Ther. 2014, 28, 33-43. [CrossRef] [PubMed]

27. Zhang, M.; Wang, S.; Cheng, Z.; Xiong, Z.; Lv, J.; Yang, Z.; Li, T.; Jiang, S.; Gu, J.; Sun, D.; et al. Polydatin ameliorates diabetic cardiomyopathy via Sirt3 activation. Biochem. Biophys. Res. Commun. 2017, 493, 1280-1287. [CrossRef] [PubMed]

28. Kanwal, A.; Pillai, V.B.; Samant, S.; Gupta, M.; Gupta, M.P. The nuclear and mitochondrial sirtuins, Sirt6 and Sirt3, regulate each other's activity and protect the heart from developing obesity-mediated diabetic cardiomyopathy. FASEB J. Off. Publ. Fed. Am. Soc. Exp. Biol. 2019, 33, 10872-10888. [CrossRef]

29. Ni, T.; Lin, N.; Huang, X.; Lu, W.; Sun, Z.; Zhang, J.; Lin, H.; Chi, J.; Guo, H. Icariin Ameliorates Diabetic Cardiomyopathy Through Apelin/Sirt3 Signalling to Improve Mitochondrial Dysfunction. Front. Pharmacol. 2020, 11, 256. [CrossRef] [PubMed]

30. Diao, Z.; Ji, Q.; Wu, Z.; Zhang, W.; Cai, Y.; Wang, Z.; Hu, J.; Liu, Z.; Wang, Q.; Bi, S.; et al. SIRT3 consolidates heterochromatin and counteracts senescence. Nucleic Acids Res. 2021, 49, 4203-4219. [CrossRef]

31. Li, Y.; Wei, X.; Liu, S.L.; Zhao, Y.; Jin, S.; Yang, X.Y. Salidroside protects cardiac function in mice with diabetic cardiomyopathy via activation of mitochondrial biogenesis and SIRT3. Phytother. Res. 2021, 35, 4579-4591. [CrossRef]

32. Ding, Y.; Yang, H.; Wang, Y.; Chen, J.; Ji, Z.; Sun, H. Sirtuin 3 is required for osteogenic differentiation through maintenance of PGC-1a-SOD2-mediated regulation of mitochondrial function. Int. J. Biol. Sci. 2017, 13, 254-264. [CrossRef] [PubMed]

33. Liang, H.; Ward, W.F. PGC-1alpha: A key regulator of energy metabolism. Adv. Physiol. Educ. 2006, 30, 145-151. [CrossRef]

34. Kong, X.; Wang, R.; Xue, Y.; Liu, X.; Zhang, H.; Chen, Y.; Fang, F.; Chang, Y. Sirtuin 3, a new target of PGC-1alpha, plays an important role in the suppression of ROS and mitochondrial biogenesis. PLoS ONE 2010, 5, e11707. [CrossRef] [PubMed]

35. Naaz, S.; Mishra, S.; Pal, P.K.; Chattopadhyay, A.; Das, A.R.; Bandyopadhyay, D. Activation of SIRT1/PGC $1 \alpha /$ SIRT3 pathway by melatonin provides protection against mitochondrial dysfunction in isoproterenol induced myocardial injury. Heliyon $\mathbf{2 0 2 0}$ 6, e05159. [CrossRef]

36. Fang, W.J.; Wang, C.J.; He, Y.; Zhou, Y.L.; Peng, X.D.; Liu, S.K. Resveratrol alleviates diabetic cardiomyopathy in rats by improving mitochondrial function through PGC-1 $\alpha$ deacetylation. Acta Pharmacol. Sin. 2018, 39, 59-73. [CrossRef]

37. Singh, S.P.; McClung, J.A.; Bellner, L.; Cao, J.; Waldman, M.; Schragenheim, J.; Arad, M.; Hochhauser, E.; Falck, J.R.; Weingarten, J.A.; et al. CYP-450 Epoxygenase Derived Epoxyeicosatrienoic Acid Contribute To Reversal of Heart Failure in Obesity-Induced Diabetic Cardiomyopathy via PGC-1 $\alpha$ Activation. Cardiovasc. Pharmacol. Open Access 2018, 7, 233. [CrossRef]

38. Wang, H.; Bei, Y.; Lu, Y.; Sun, W.; Liu, Q.; Wang, Y.; Cao, Y.; Chen, P.; Xiao, J.; Kong, X. Exercise Prevents Cardiac Injury and Improves Mitochondrial Biogenesis in Advanced Diabetic Cardiomyopathy with PGC-1 $\alpha$ and Akt Activation. Cell. Physiol. Biochem. Int. J. Exp. Cell. Physiol. Biochem. Pharmacol. 2015, 35, 2159-2168. [CrossRef] [PubMed]

39. Mollica, G.; Senesi, P.; Codella, R.; Vacante, F.; Montesano, A.; Luzi, L.; Terruzzi, I. L-carnitine supplementation attenuates NAFLD progression and cardiac dysfunction in a mouse model fed with methionine and choline-deficient diet. Dig. Liver Dis. 2020, 52, 314-323. [CrossRef] [PubMed]

40. Dong, X.; He, Y.; Ye, F.; Zhao, Y.; Cheng, J.; Xiao, J.; Yu, W.; Zhao, J.; Sai, Y.; Dan, G.; et al. Vitamin D3 ameliorates nitrogen mustard-induced cutaneous inflammation by inactivating the NLRP3 inflammasome through the SIRT3-SOD2-mtROS signaling pathway. Clin. Transl. Med. 2021, 11, e312. [CrossRef] [PubMed]

41. Traba, J.; Geiger, S.S.; Kwarteng-Siaw, M.; Han, K.; Ra, O.H.; Siegel, R.M.; Gius, D.; Sack, M.N. Prolonged fasting suppresses mitochondrial NLRP3 inflammasome assembly and activation via SIRT3-mediated activation of superoxide dismutase 2. J. Biol. Chem. 2017, 292, 12153-12164. [CrossRef]

42. Wu, C.Y.; Hua, K.F.; Yang, S.R.; Tsai, Y.S.; Yang, S.M.; Hsieh, C.Y.; Wu, C.C.; Chang, J.F.; Arbiser, J.L.; Chang, C.T.; et al. Tris DBA ameliorates IgA nephropathy by blunting the activating signal of NLRP3 inflammasome through SIRT1- and SIRT3-mediated autophagy induction. J. Cell. Mol. Med. 2020, 24, 13609-13622. [CrossRef] [PubMed] 
43. Xia, B.; Tong, Y.; Xia, C.; Chen, C.; Shan, X. $\alpha$-Cyperone Confers Antidepressant-Like Effects in Mice via Neuroplasticity Enhancement by SIRT3/ROS Mediated NLRP3 Inflammasome Deactivation. Front. Pharmacol. 2020, 11, 577062. [CrossRef] [PubMed]

44. Ulven, S.M.; Holven, K.B. Comparison of bioavailability of krill oil versus fish oil and health effect. Vasc. Health Risk Manag. 2015, 11, 511-524. [CrossRef] [PubMed]

45. Terruzzi, I.; Vacante, F.; Senesi, P.; Montesano, A.; Codella, R.; Luzi, L. Effect of Hazelnut Oil on Muscle Cell Signalling and Differentiation. J. Oleo Sci. 2018, 67, 1315-1326. [CrossRef] [PubMed] 